\title{
Indicadores de desempenho da Aduana do Brasil: em busca de uma abordagem equilibrada
}

\section{Towards a balanced approach in the performance indicators of the Brazilian customs}

\author{
Cristiano Morini \\ Edmundo Inácio Júnior ${ }^{1}$ \\ Luis Antonio de Santa-Eulália² \\ Milena Pavan Serafim ${ }^{1}$
}

\begin{abstract}
Resumo: A aquisição de insumos produtivos no mercado internacional é prática corrente em cadeias de suprimentos globais, com as operações logísticas incluindo atividades de importação e exportação. Assim, a aduana é um elo que deve ser considerado na gestão global de cadeias de suprimentos. Tais atividades são normalmente complexas, uma vez que estão sujeitas a requisitos aduaneiros diferenciados por país. Neste contexto, a aduana brasileira é posicionada como de baixa competitividade em vários rankings produzidos por organismos internacionais. São escassos os estudos sobre administração aduaneira (aduana) no Brasil, sendo que não existem pesquisas abordando medição de desempenho neste contexto. Sendo assim, este trabalho objetiva apresentar indicadores de desempenho utilizados por administrações aduaneiras em todo o mundo, bem como compará-los com a realidade da aduana do Brasil e discutir potenciais benefícios ao país na adoção de uma nova abordagem alinhada com as melhores práticas internacionais. Como pesquisa qualitativa do tipo exploratória, foi feita uma comparação dos indicadores de desempenho utilizados como melhores práticas e os indicadores brasileiros. A coleta de dados utilizou indicadores de desempenhos levantados por organizações internacionais. Por parte da aduana brasileira, foi feita consulta pública ao Ministério da Fazenda, utilizando-se da Lei de Acesso à Informação, além de Relatórios de Gestão da Receita do Brasil, órgão responsável pela administração tributária e aduaneira. Esta temática se mostra particularmente relevante no Brasil, pois os indicadores utilizados até então privilegiam a arrecadação e os controles (com práticas relacionadas ao enforcement) e não o nível de serviço prestado ao contribuinte (com práticas relacionadas ao compliance e ao service charter), tal como utilizado em países com elevado desempenho aduaneiro. Como resultado, a análise dos indicadores utilizados no Brasil evidencia a necessidade de reforma do sistema aduaneiro, privilegiando uma abordagem equilibrada no enforcement e no compliance, de modo a contribuir para ganhos de competitividade em cadeias internacionais que passam pelo país.
\end{abstract}

Palavras-chave: Medição de desempenho; Operações logísticas; Cadeias de suprimentos internacionais; Comércio internacional.

\begin{abstract}
Procurement in international markets is a current practice in today's global supply chains, leading logistics operations to include import and export activities in their procurement process. Such activities are usually of complex nature, since they are subject to diverse customs requirements in different countries. In this context, Brazilian customs is ranked low in terms of competitiveness according to various international organizations. However, published studies on customs administration in Brazil are rare, and there is no research addressing performance measurement in the specialized literature. Thus, this paper aims to present and discuss performance indicators employed by customs administrations around the world, with a special attention to Brazil. Customs is part of a global supply chain management. As an exploratory qualitative research, this manuscript provides a comparison of performance indicators employed in Brazil against those used by countries with high-performance customs. A set of performance indicators was selected according to international standards. Data concerning Brazilian customs was collected from the Ministry of Finance, using the Law on Access to Information, and published Management Reports related to the Brazilian Revenue Authority, in charge of tax and customs administration. This topic is relevant in Brazil because the indicators used so far favour tax collection and controls (related to "enforcement practices") to the detriment of the service level provided to the taxpayer (related to "compliance practices" and the "service
\end{abstract}

${ }^{1}$ Faculdade de Ciências Aplicadas - FCA, Universidade Estadual de Campinas - Unicamp, Rua Pedro Zaccaria, 1300, Jardim Santa Luiza, CEP 13484-350, Limeira, SP, Brasil, e-mails: cristiano.morini@fca.unicamp.br; edmundo.inacio@fca.unicamp.br; milena.serafim@fca.unicamp.br

${ }^{2}$ Faculté d administration, Université de Sherbrooke, Quebec, Canadá, e-mail: luis.antonio.de.santa-eulalia@usherbrooke.ca Recebido em Abr. 26, 2014 - Aceito em Nov. 20, 2014

Suporte financeiro: FAPESP, CNPq. 
charter"), as used in countries with high customs performance. As a result, this paper puts into evidence the need to reform the Brazilian customs system, favouring a balanced approach combining "enforcement" and "compliance" in order to increase the competitiveness of international supply chains crossing this country.

Keywords: Performance measurement; Logistics operations; International supply chains; International trade.

\section{Introdução}

O debate sobre o processo de globalização comercial e produtiva vem ganhando espaço nas agendas de decisão dos governos nas últimas décadas. A liberalização financeira e cambial, a mudança nos padrões de concorrência capitalista e a alteração das regras institucionais do comércio e do investimento geraram uma crescente disputa por competitividade, em um ambiente empresarial complexo, com a necessidade de atuação/regulação por parte do Estado (Levitt, 1983; Ruigrok \& van Tulder, 1995; Baumann, 1996). Se, pelo lado das empresas, passam a ser exigidas habilidades, estratégias e vantagens competitivas capazes de garantir eficiência e lucratividade, pelo lado dos Estados nacionais passa a ser exigida uma racionalização da gestão em busca de uma administração pública mais efetiva socialmente, eficiente no uso dos recursos e eficaz, com atenção para o serviço prestado ao contribuinte (Pomfret, 2010).

Um dos setores que impacta diretamente no fortalecimento do comércio exterior e na competitividade das empresas é a administração aduaneira (ou aduana). No Brasil, esta organização pública é o principal agente de mediação no trânsito internacional de mercadorias pelas fronteiras do país. A aduana desempenha funções no sentido de defender os interesses do Estado (segurança contra ameaças; contrabandos; trânsito ilegal de armas e drogas; arrecadação) e de facilitar e agilizar as operações de importação e exportação, fundamentais para o desenvolvimento do país (Heaver, 1992; Gregorio, 2001; Lima, 2008; Ireland \& Matsudaira, 2011).

A esfera aduaneira no Brasil possui algumas características peculiares, em especial a sua estrutura de governança, ligada à Secretaria da Receita Federal do Brasil (RFB) e ao Ministério da Fazenda. Esta alocação do controle aduaneiro no seio da RFB torna o controle aduaneiro no Brasil com uma ênfase no controle e na arrecadação, o que impacta diretamente na estratégia de controle do fluxo de mercadorias pelo país. Historicamente, a administração tributária e aduaneira estiveram, em grande parte, sob o mesmo órgão gestor (Vital, 2014). Seus traços históricos de arrecadação e combate a práticas ilegais favorece a ênfase em indicadores de enforcement (repressão aduaneira). No entanto, as boas práticas observadas nas administrações aduaneiras de outros países caminham para uma abordagem equilibrada, considerando questões e indicadores relacionados também a compliance (estímulo ao cumprimento voluntário de normas), em que o cliente também é ouvido e chamado a colaborar, o que tem sido chamado, em inglês, de service charter (Bourne et al., 2000; WCO, 2012). Isto se dá porque o excessivo foco no indicador "arrecadação" não contribui para ganhos de competitividade de empresas que realizam operações em cadeias de suprimentos internacionais. A utilização de indicadores de desempenho na área de níveis de serviço ao contribuinte pode levar a ganhos de competitividade do país.

Outro argumento que demonstra a relevância da pesquisa é a baixa posição comparativa da aduana brasileira em rankings internacionais produzidos por organizações internacionais, como os produzidos pelo World Economic Forum (Global Competitiveness Index e Global Enabling Trade Report), pelo Institute of Management Development (IMD World Competitiveness Center), pelo Banco Mundial (Doing Business - Trading Across Borders - e Logistics Performance Index - LPI), pelo Departamento de Competitividade e Tecnologia (DECOMTEC) da Federação das Indústrias do Estado de São Paulo (FIESP), e por outras organizações internacionais (e.g. Agility Emerging Markets Logistics Index), entre outros.

Estudos complementares, cruzando dados dos vários rankings e realizando análise envoltória de dados (DEA), apresentam a aduana brasileira em posição de mais baixa eficiência relativa, considerando amostra de 50 países, o que justifica a necessidade de reformas no ambiente aduaneiro no Brasil (Morini et al., 2014). Independentemente da metodologia do ranking utilizado, e mesmo considerando que todo ranking pode ser questionado pelos critérios adotados, a questão dos serviços aduaneiros é considerada aspecto-chave para a competitividade de cadeias de suprimentos internacionais.

Em todos os rankings mencionados, a aduana brasileira é posicionada como de baixa competitividade. Um dos resultados identificados por esta pesquisa é que os rankings internacionais e as metodologias utilizadas para medir o serviço prestado pela aduana são focados em um conjunto de indicadores relacionados no nível de serviço entregue ao cliente (service charter) e não no nível de receita gerada pela arrecadação dos tributos relativos às operações internacionais de importação. Como são dois enfoques distintos, a supervalorização em um deles proporciona baixa competitividade em outro, como é 
o caso da aduana do Brasil, conforme será discutido em termos de indicadores de desempenho utilizados pela administração aduaneira.

Apesar da importância do assunto, a literatura científica e profissional carece de estudos sobre indicadores de desempenho do sistema aduaneiro brasileiro. Em especial, não existem análises comparativas sobre indicadores privilegiados pelo país, em relação aos indicadores empregados pelos países referência na área.

Sendo assim, o presente estudo apresenta uma contribuição para o entendimento da aduana brasileira no contexto de cadeias de suprimentos globais, especialmente no tema dos indicadores de desempenho. Propõe-se que a ênfase nos controles, com fins arrecadatórios e na repressão aduaneira, com a imposição da força (enforcement), deva ser equilibrada com os outros tipos de indicadores. Isto poderá beneficiar o fluxo de mercadorias e permitir a participação, com mais competitividade, de empresas sediadas no Brasil que realizam operações logísticas internacionais, com base no estímulo ao cumprimento voluntário das normas (compliance) e no nível de serviço entregue (pela aduana) ao cliente (os operadores econômicos envolvidos), conceito relativo ao service charter.

A relevância prática deste estudo está baseada na constatação de que grande parte dos operadores econômicos (importadores, exportadores, transportadores, operadores logísticos e outros), que realiza atividades no Brasil, com destaque para as empresas multinacionais, utiliza-se da aquisição de insumos no mercado externo, o que se dá por meio das importações. Este processo de entrada de mercadorias é centrado em uma burocracia com fins fiscalistas, que agrega tempo e não agrega valor (Djankov et al., 2010; Haughton \& Desmeules, 2001). Vários são os estudos produzidos por organizações internacionais em que esta característica transparece, como estudos produzidos pelo Banco Mundial, Fórum Econômico Mundial e Organização Mundial das Aduanas (GCI, 2008; Lawrence et al., 2012; Matsuda, 2012; Banco Mundial, 2014; The World Bank, 2014).

Visando melhorar tal situação, a utilização de indicadores de desempenho adequados mostra-se útil para orientar a administração na elaboração de estratégias, além de estabelecer metas em termos de melhoria de serviços prestados, indicar caminhos e práticas aceitáveis e contribuir para a previsibilidade dos serviços prestados pelos órgãos públicos, embora não haja uniformidade em quais indicadores devam ser priorizados e embora os operadores econômicos e autoridades aduaneiras tendam a divergir sobre as prioridades em termos de metas e análise de indicadores de desempenho na aduana (Appeals \& Struye de Swielande, 1998; Gubin, 2011).
Buscando contribuir com o debate exposto, este trabalho tem como objetivo apresentar, discutir e comparar a abordagem de indicadores de desempenho na aduana brasileira em contexto de cadeias de suprimentos internacionais. De natureza exploratória, este trabalho envolve pesquisa bibliográfica (Silva \& Menezes, 2005), realizada por meio de uma revisão sistemática da literatura (Cook et al., 1997) nas seguintes bases de dados: Web of Science, Ebsco, Emerald, Elsevier, Sage, Wiley e Scielo, incluindo os termos "customs" (equivalente em português à "aduana" ou "alfândega") "e" "performance indicators" (além de derivados, como "customs administration" "e" "performance measurement". Os termos "aduana" e "alfândega" também foram pesquisados, cobrindo um horizonte de 15 anos (2000-2014). Além disso, o trabalho também envolve pesquisa documental (Silva $\&$ Menezes, 2005) junto à aduana brasileira feita por meio de consulta pública ao Ministério da Fazenda, utilizando-se da Lei de Acesso à Informação, além de Relatórios de Gestão da Receita do Brasil, órgão responsável pela administração tributária e aduaneira. A pesquisa documental também se estendeu a diversos relatórios publicados por organismos internacionais, incluindo a Organização Mundial das Aduanas, o Banco Mundial, o Fórum Econômico Mundial, a Organização Mundial do Comércio e a Câmara Internacional de Comércio.

Assim, organiza-se o trabalho em quatro partes, além desta introdução e das considerações finais. $\mathrm{Na}$ primeira parte, são apresentados conceitos de cadeia de suprimentos, a fim de contextualizar a importância das administrações aduaneiras como um agente catalisador e limitador no processo de aquisição de insumos das cadeias de suprimentos internacionais. Em seguida, debate-se o papel do monitoramento e avaliação na ação governamental, o uso de indicadores de desempenho e sua aplicação à administração aduaneira. Na terceira parte, é apresentado um estudo sobre indicadores de desempenho na logística internacional, especialmente no que diz respeito à entrada de mercadorias em um país, fazendo referência à medição de desempenho em aduanas. Na quarta parte, é analisado o perfil de indicadores utilizados na medição do desempenho da aduana brasileira, com base em pesquisa realizada por meio da ferramenta da Lei de Acesso à Informação. E, por fim, algumas considerações finais são tecidas.

\section{Cadeia de suprimentos e o papel das Aduanas}

A cadeia de suprimentos, segundo Ballou (2006), é o conjunto de atividades funcionais que se repetem várias vezes ao longo do processo em que as matérias-primas vão sendo convertidas em produtos acabados, agregando valor ao consumidor. 
Nesta cadeia, as matérias-primas são adquiridas, manufaturadas em fábricas, movidas para depósitos, armazenadas e finalmente despachadas para os clientes finais (Kaminsky et al., 2003; Cooper et al., 1997). Nesse sentido, a cadeia de suprimentos desempenha uma importante função de integração, interligando os diversos agentes da cadeia - os "nós" - entre si, por intermédio do fluxo de informações e matérias-primas por eles estabelecido - as "ligações" -, traduzindo-se, portanto, em uma poderosa ferramenta competitiva (Corrêa, 2010). Obviamente, o resultado geral da cadeia, medido em termos de eficiência e atendimento às expectativas dos clientes, dependerá da escolha estratégica (Child, 1972, 1997) que seus vários "nós" realizarão com relação a aspectos relacionados à coordenação, cooperação e integração, entre vários outros (Bowersox et al., 2006).

A gestão de cadeias de suprimentos internacionais envolve decisões estratégicas que perpassam mais de um país e, portanto, diferentes tipos de políticas, culturas, leis e processos burocráticos, tornando os processos e operações mais complexos. Arvis et al. (2012) destacam que para uma empresa ser competitiva, é necessário entender outros fatores que estão diretamente em contato com a cadeia de suprimentos, que, segundo Lawrence et al. (2012) e Portugal-Perez \& Wilson (2010), estão relacionados às questões hard e a questões soft do comércio internacional. $\mathrm{O}$ hard está relacionado à questão de infraestrutura de apoio à movimentação de mercadorias. O soft está relacionado a procedimentos e trâmites aduaneiros que podem provocar interrupções e atrasos imprevisíveis no fluxo internacional de mercadorias pelas fronteiras. Para Nguyen (2012), é necessário um sistema confiável para as companhias que atuam no mercado internacional, sendo que a imprevisibilidade nos controles aduaneiros não contribui para uma boa performance das cadeias.

A título de exemplo, Mestriner (2010) cita alguns fatores em que a cadeia de suprimentos internacional está submetida, entre eles: diferenças de infraestrutura; decisões relacionadas ao transporte internacional; maior número de intermediários envolvidos; diferentes exigências burocráticas por agentes públicos intervenientes; riscos e danos mais significativos; meios de pagamentos internacionais; e, questões de desembaraço aduaneiro.

No que se refere ao Brasil, o processo de entrada de mercadorias no país é considerado burocrático, devido à complexidade dos procedimentos aduaneiros, em geral relacionados a documentos que devem ser apresentados e informações duplicadas, entre outros fatores (The World Bank, 2014). Ainda que parte dos procedimentos esteja informatizada e relativamente unificada em um sistema denominado Sistema Integrado de Comércio Exterior (SISCOMEX), os sistemas informatizados não estão totalmente sincronizados.
No SISCOMEX, alguns órgãos governamentais ficam interligados aos agentes que têm participação nos processos e controles requeridos. No entanto, no Brasil, segundo Morini \& Leoce (2011), há cerca de 40 órgãos públicos que intervêm nas atividades de controle e movimentação de carga pelas fronteiras, atuando de forma não plenamente sincronizada, sendo que ainda estão em fase de implementação ações no sentido de concretizar o conceito de "guichê único" (single window) para o comércio exterior do Brasil.

Outra característica marcante do sistema aduaneiro brasileiro está ligada ao fato de que a Secretaria da Receita Federal do Brasil (RFB) é responsável pela administração aduaneira e tributária. No Brasil, o artigo 237 da Constituição Federal de 1988, que norteia a fiscalização e o controle do comércio exterior, estabelece que esta função compete ao Ministério da Fazenda. Isto faz com que o controle aduaneiro no Brasil apresente, historicamente, maior ênfase nos princípios da seletividade, da fiscalização estruturada em procedimentos diferenciados de intervenção, da integração com os controles de tributos internos, do uso de força de vigilância e repressão, ou na repressão aos crimes transfronteiriços, dentre outros (Brasil, 2012c). Ainda que tenha existido um forte crescimento e desenvolvimento das operações aduaneiras nos últimos anos, de acordo com a própria Receita Federal do Brasil (2012a), o mesmo não foi acompanhado por uma efetiva modernização da gestão, com ênfase no serviço entregue ao cliente. É particularmente importante notar que seus instrumentos de medição de desempenho enfatizam os indicadores de arrecadação, controles e enforcement. De acordo com van Stolk $\&$ Wegrich (2008), qualquer sistema de indicadores de desempenho deve estar conforme alguns padrões e critérios desenhados, de modo que os indicadores refletem aspectos relevantes das características da organização.

$\mathrm{O}$ argumento deste artigo, tratado em detalhes nas próximas seções, é que a modernização da administração aduaneira deve passar da ênfase no controle para a ênfase na cooperação e prestação de serviço ao contribuinte, estimulando boas práticas e o cumprimento voluntário das normas (compliance), o que pode melhorar a competitividade das cadeias de suprimentos internacionais que passam pelo Brasil.

Excessivos controles na aduana podem tornar-se uma barreira não tarifária, com impactos em termos de tempo e custos relacionados (Sawhney \& Sumukadas, 2005; Liu \& Yue, 2013). A ênfase fiscalista e de controle é relacionada ao combate às práticas fraudulentas e ilegais (chamada também de enforcement), enquanto a cooperação com o agente privado passa a espelhar a nova realidade de um mundo globalizado, em que mercadorias cruzam fronteiras, seja com a presença de fornecedores no exterior, seja com relação aos clientes. Esta nova 
ênfase da aduana (chamada de compliance) não exclui a ênfase anterior (enforcement), mas precisa ser equilibrada para refletir uma nova realidade de globalização e competitividade internacional. Neste contexto, é relevante que as administrações aduaneiras e os serviços por elas prestados sejam medidos e devidamente analisados, com uma ênfase equilibrada. A utilização de uma abordagem equilibrada pela aduana brasileira possibilitaria o sincronismo com os principais indicadores utilizados em termos de competitividade em cadeias de suprimentos internacionais, com consequente melhoria na qualidade da posição comparativa do Brasil em rankings internacionais. A melhora do posicionamento do Brasil nestes rankings não é relevante pelo ranking em si, mas pelo reflexo de boas práticas sendo adotadas, em sintonia com as melhores práticas internacionais na área e com a alocação de recursos de maneira mais efetiva.

\section{Avaliação e indicadores de desempenho}

$\mathrm{O}$ crescente interesse dos governos nos estudos de avaliação de sistemas aduaneiros está atrelado às mudanças institucionais recentes que a administração pública passou nos últimos anos (especialmente na década de 1990). A consolidação do planejamento governamental, o aprimoramento dos controles administrativos, em especial dos Tribunais de Contas, a preocupação com a efetividade, eficiência, accountability e desempenho da administração pública conformaram um terreno fértil para a preocupação com avaliações focadas tanto no desempenho da ação governamental, quanto no cumprimento legal (Modell, 2001; Jannuzzi, 2005).
Tradicionalmente, os estudos das políticas públicas têm empregado o modelo do ciclo da política (policy cycle) que estiliza o processo de elaboração das políticas públicas. Para autores como Jones (1970), Dye (1976), Meny \& Thoenig (1992), Frey (2000), Roth Deubel (2006) e Serafim \& Dias (2012), o ciclo da política seria constituído pela sucessão de cinco momentos sucessivos, dinâmicos e interligados: i) identificação do problema; ii) conformação da agenda; iii) formulação; iv) implementação; v) avaliação.

Apesar de a avaliação estar como o "último" momento do "policy cycle" (ciclo da política), ela não necessariamente ocorre após a implementação da política (avaliação ex-post). A avaliação pode ocorrer também no início do ciclo (avaliação ex-ante) ou ao longo dele (avaliação concomitante ou monitoramento). A Figura 1 espelha o ciclo da política pública e indica o uso sistemático de dados e indicadores como embasamento constante no processo de elaboração e revisão de uma ação governamental.

Assim, a avaliação se apresenta como um instrumento técnico que permite o desenvolvimento de processos para a revisão e medição sistemática do estado do problema e do curso da ação governamental. Os resultados dessa avaliação podem ocasionar três situações: i) auxiliar a melhoria da ação/política e, assim, a sua continuação; ii) finalizar a ação/política existente; e iii) desenvolver uma nova ação/política. Além de instrumento técnico, a avaliação é também uma ferramenta política. Os resultados dela são utilizados para melhorar as ações e para prestar contas (accountability) aos cidadãos, contribuindo assim para a confiança e para a legitimidade do sistema (Serafim \& Dias, 2012).

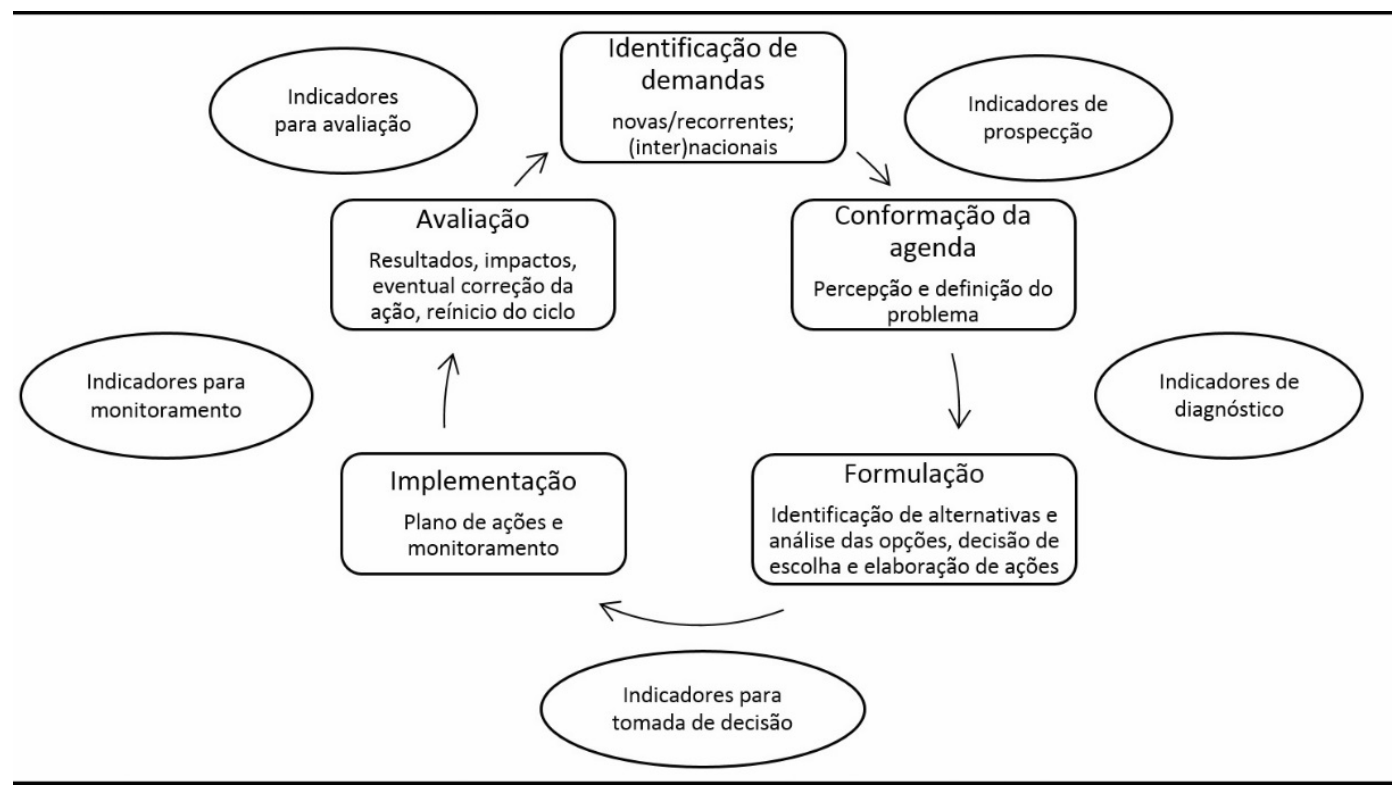

Figura 1. Ciclo de Políticas Públicas. Fonte: Elaborado pelos autores, a partir de Jannuzzi (2005). 
Para isso, uma avaliação só será um instrumento completo se contemplar múltiplas dimensões de análise (insumos - processos - resultados). Enquanto a dimensão insumos foca a avaliação dos recursos, habilidades e pessoas que participam de uma determinada ação, a dimensão processos foca o desenho, nas características organizacionais e de desenvolvimento das ações/atividades. O objetivo desta dimensão é detectar os fatores que, ao longo da implementação, facilitam ou impedem que um dado programa atinja seus resultados da melhor maneira possível. Já a dimensão resultados possui o foco no desempenho das ações/atividades (resultados produzidos e mudanças na realidade), cujo objetivo é levantar metas atingidas, resultados alcançados e efeitos produzidos (Roth Deubel, 2006). Uma avaliação que contemple esse conjunto de dimensões busca avaliar o desempenho (implementação e resultados), com vistas à eficiência, efetividade, impacto e sustentabilidade, de uma determinada ação ou instituição.

Essas dimensões de análise são medidas por meio de indicadores - recursos metodológicos de base empírica - que procuram descrever/mensurar um determinado fenômeno ou aspecto da realidade (Jannuzzi, 2003). O Tribunal de Contas da União apresenta que "[...] indicador de desempenho é um número, porcentagem ou razão que mede um aspecto do desempenho, com a finalidade de comparar esta medida com metas preestabelecidas [...]" (Brasil, 2009, p. 4).

Para o Guia Referencial para Medição de Desempenho e Manual para Construção de Indicadores da Secretaria de Gestão (SEGES), do Ministério do Planejamento, os indicadores possuem duas funções: "[...] a primeira é descrever [...] o estado real dos acontecimentos e o seu comportamento; a segunda [...] consiste em analisar as informações presentes, com base nas anteriores, de forma a realizar proposições valorativas [...]" (Brasil, 2009, p. 12). Este Guia estrutura a avaliação e seus indicadores em dois grandes grupos - Esforço e Resultado - que se subdividem em 6 (seis) itens ou 6 (seis) "Es" do Desempenho (Brasil, 2009), os quais estão descritos no Quadro 1.

No âmbito do esforço, a economicidade diz respeito à utilização e obtenção de recursos com o menor custo possível (de acordo com os requisitos exigidos); a execução indica a realização das atividades conforme previsto; e a excelência corresponde à conformidade aos padrões de qualidade durante a execução das atividades, buscando melhor execução e economicidade (Brasil, 2009).

Em relação ao resultado, a eficiência relaciona os outputs com os insumos utilizados; a eficácia corresponde à quantidade e a qualidade dos produtos ou serviços entregues; e a efetividade indica os impactos gerados pelas atividades finais (Brignall \& Modell, 2000; Brasil, 2009).
Para a formulação de indicadores de desempenho, alguns passos podem ser seguidos (Brasil, 2009):

1. Identificar níveis e objetos de mensuração

2. Estabelecer indicadores de desempenho

3. Validar indicadores com as partes interessadas

4. Construir fórmulas e estabelecer metas

5. Definir responsáveis

6. Sistemas de coleta de dados

7. Validação final dos indicadores junto às partes interessadas

8. Mensurar resultados

9. Analisar e interpretar indicadores

10. Comunicação do desempenho e gestão de mudança.

Ainda que a construção de indicadores de desempenho não siga uma metodologia padrão, os passos acima identificados podem servir como um guia para a elaboração e utilização de tal ferramenta.

Em relação à medição de desempenho em gestão da cadeia de suprimentos, conceitos simulares da gestão pública são utilizados. Neste caso, as medidas de desempenho também são importantes para uma gestão eficaz e fornecem a avaliação necessária de fatores relacionados ao custo e serviços da execução da logística na cadeia de suprimentos (Griffis et al., 2007; Shepherd \& Wilson, 2009).

De acordo com Gunasekaran et al. (2004), as métricas a serem utilizadas na medição de desempenho devem ser aquelas que capturam a essência do desempenho organizacional. Neste sentido, considera-se que a avaliação de desempenho está inserida em um contexto singular (Beamon, 1999; Abernethy et al., 2005; Lacerda et al., 2012) e é utilizada para analisar processos (Balasubramanian \& Gupta, 2005), identificar pontos fortes e fracos do ambiente, melhorar a aprendizagem contínua (Chin et al., 2010), e incluir as preocupações dos stakeholders do negócio ou do serviço público.

No caso da cadeia de suprimentos, as medidas de desempenho estão focadas em metas a serem cumpridas ao longo dos processos, o que pode levar em consideração especialmente o lead time e a gestão de estoque, por exemplo (Lai et al., 2002). De acordo com Piotrowicz et al. (2011), existem vários métodos especializados para medir o desempenho na cadeia de suprimentos. Essas medidas e métricas

Quadro 1. Grupos de abordagens do manual para construção de indicadores.

\begin{tabular}{|c|c|}
\hline Esforço & Resultado \\
\hline$\bullet$ Economicidade & $\bullet$ Eficiência \\
\hline$\bullet$ Execução & $\bullet$ Eficácia \\
\hline$\bullet$ Excelência & $\bullet$ Efetividade \\
\hline
\end{tabular}

Brasil (2009). 
são necessárias para testar e mostrar a viabilidade de algumas estratégias. Sem tal medição, seria contraproducente obter uma direção clara para a realização dos objetivos. Além disso, em geral, há falta de uma distinção clara entre as métricas para os níveis estratégico, tático e operacional (Parker, 2000; De Toni \& Tonchia, 2001; Pascal, 2010). O Quadro 2 resume algumas métricas que podem ser utilizadas para a avaliação de desempenho em cadeias de suprimentos.

Entre os itens observados no Quadro 2, pode-se destacar alguns indicadores de desempenho utilizados para a avaliação na cadeia de suprimentos, os quais são influenciados pela gestão aduaneira:

a) Lead time do pedido: trata-se do tempo total do ciclo de um pedido, ou seja, desde o recebimento do pedido do cliente até a entrega do produto final. A redução nesse tempo total também reduz o tempo total do processo, melhorando o nível de serviço ao cliente.

b) Custo de estoque: é importante medir os aspectos relacionados aos meios de entrega e programação dos canais e transportes. Falta de previsibilidade e consistência nos fluxos internacionais de mercadorias provoca o efeito de carregar mais o estoque, a fim de evitar falta de material.

c) Flexibilidade: indica tornar os produtos ou serviços disponíveis para atender à demanda individual dos consumidores, mesmo quando esta varia em termos de volume, datas ou tipos de produtos e serviços.

d) Qualidade e satisfação do cliente: medição do serviço prestado pela aduana a partir da satisfação do usuário/clientes dos serviços. Essa incorporação da percepção do usuário na racionalidade dos serviços governamentais ocorreu nos anos 1990 a partir da crítica da falta de qualidade nos serviços prestados. O movimento chamado de "nova gestão pública", ou new public management (NPM) (Brignall \& Modell, 2000; WCO, 2012) requeria, dentre outras mudanças, a inclusão dessa racionalidade no setor público. Uma das estratégias da NPM são os service charters, no sentido de mudar a cultura do serviço, de prestado para focado no cliente (Gültekin, 2011).

A gestão inadequada desses indicadores pode potencializar um efeito negativo clássico na área de gestão de cadeia de suprimentos, conhecido na literatura como efeito chicote (Forrester, 1961). Neste contexto, nota-se a importância do sistema aduaneiro e o impacto no fluxo de mercadorias de um país, os quais influenciam no tempo de processamento do pedido, produção e entrega final. Quanto menor o tempo associado ao desembaraço aduaneiro das mercadorias, mais rápida é a entrega, de forma que a produção e a entrega final possam ser realizadas na direção de atender melhor às necessidades dos clientes em relação aos concorrentes potenciais. Sendo assim, acredita-se que o efeito chicote pode ser reduzido.

Dessa forma, é relevante que as operações aduaneiras estejam atreladas aos sistemas de medição de desempenho - indicadores - que devem ser utilizados para verificar os níveis de desempenho dos processos e buscar oportunidades de melhorias que possam resultar na diminuição do tempo de desembaraço aduaneiro total, entre outras, considerando também os interesses dos stakeholders de uma cadeia de suprimentos internacional (operadores logísticos, despachantes aduaneiros, terminais portuários, agentes de carga, empresas clientes e consumidores).

\section{Referenciais de utilização de indicadores de desempenho em Aduanas}

A medição de desempenho é importante para obter sucesso na modernização dos processos aduaneiros (Ireland et al., 2011). Os motivos pelos quais as aduanas dos países utilizam a medição de desempenho são variados, dentre eles a busca por redução de custos por meio da melhoria na eficiência, o desenvolvimento de transparência e políticas associadas, a avaliação do trabalho individual como parte do processo de

Quadro 2. Métricas para Avaliação de Desempenho em cadeias de suprimentos, influenciadas pelo desempenho da aduana.

\begin{tabular}{|l|l|l|}
\hline \multicolumn{1}{|c|}{ Produtividade } & \multicolumn{1}{|c|}{ Custo } & \multicolumn{1}{c|}{$\begin{array}{c}\text { Qualidade, Serviço e } \\
\text { Satisfação do Cliente }\end{array}$} \\
\hline • Produtividade dos armazéns & $\bullet$ Custo total de inventário & $\bullet$ Flexibilidade \\
\hline - Utilização da capacidade & $\bullet$ Custo total de distribuição & $\bullet$ Nível de satisfação do cliente \\
\hline$\bullet$ Eficácia das técnicas de programação & $\begin{array}{l}\bullet \text { Custos associados a ativos e retorno } \\
\text { sobre os investimentos }\end{array}$ & $\begin{array}{l}\text { Medidas de avaliação de desempenho } \\
\text { de entrega }\end{array}$ \\
\hline$\bullet$ Lead time do pedido & $\bullet$ Custo de estoque em processo & $\bullet$ Acurácia de previsões de demanda \\
\hline & $\bullet$ Custo de transporte & \\
\hline
\end{tabular}

Adaptado de Gunasekaran et al. (2001), Kennerley \& Neely (2002) e Corrêa (2010). 
recursos humanos, a luta contra a corrupção, entre outros.

Assim, as aduanas, em sua função de controlar o fluxo de comércio exterior, devem tomar em conta outros aspectos além do controle e não podem se constituir em obstáculo ao comércio, tampouco ignorar sua importância na defesa do comércio legítimo, coibindo os ilícitos (Basaldua, 2007).

De acordo com Seth (2010), a medição de desempenho tem como papel avaliar os resultados e analisar a eficácia de certas estratégias e operações, bem como remover carências e deficiências, se houver. $\mathrm{O}$ autor faz uma associação com a palavra smart, ou seja, indica que para que esses objetivos sejam atingidos, os indicadores de desempenhos devem ser do tipo SMART - Specific purpose, Measurable, Achievable targets, Relevant for the organization, Time specific. Isso significa que os indicadores devem ter um propósito específico, ser mensuráveis, ter metas atingíveis, ser relevantes para a organização, em um tempo específico.

Há várias formas de organizar os indicadores aduaneiros, considerando várias metodologias e contextos de aplicação de indicadores. De acordo com Seth (2010), alguns dos KPIs (Key Performance Indicators) utilizados no âmbito das aduanas tratam de arrecadação de impostos (receitas), cumprimento das leis, facilitação do comércio, proteção da sociedade, gestão de risco, proteção das fronteiras, tempo de desembaraço, entre outros. Ou também podem ser agrupados em categorias, como atividades centrais da organização (arrecadação, número total de registros, informação administrativa); cumprimento das obrigações com relação ao código tarifário (taxas de erros e taxas de cumprimento voluntário da legislação); qualidade do serviço (acurácia das informações prestadas, satisfação do cliente, qualidade da interface com o cliente); e custo do serviço (produtividade, custos por tarefas, relação do número de auditores fiscais por contribuinte) (van Stolk \& Wegrich, 2008).

De forma geral, os países possuem peculiaridades em relação à medição de desempenho. No Japão, por exemplo, a facilitação do comércio é considerada a parte mais importante dos KPIs e o tempo necessário para o desembaraço aduaneiro é um indicador crítico. O mesmo ocorre no Egito, onde a redução no tempo de desembaraço é relacionada a um indicador considerado relevante pela administração aduaneira egípcia (Cho et al., 2007; Seth, 2010; Gubin, 2011).

Cantens et al. (2010), por sua vez, colocam que muitas administrações aduaneiras têm como principal problema a corrupção. Para que possa haver a redução da corrupção, devem ser formuladas políticas construtivas que colaborem simultaneamente com a melhora no desempenho aduaneiro, bem como com o fortalecimento das operações. Como exemplo principal de tais reformas, a aduana de Camarões lançou em
2007 uma iniciativa de modernização, a qual tinha o objetivo de reduzir a corrupção. O ponto inicial foi a implementação do Automated System for Customs Data (ASYCUDA), desenvolvido pela Conferência das Nações Unidas para Comércio e Desenvolvimento (UNCTAD). Este sistema de desembaraço aduaneiro permitiu a administração e o acompanhamento de cada processo, assim como a medição de grande número de critérios necessários. A partir de 2010, a aduana de Camarões implantou um sistema de "contratos de desempenho" individuais para medir de forma mais precisa as ações e comportamentos dos servidores aduaneiros que atuavam em determinados portos, usando indicadores extraídos do Asycuda (Cantens et al., 2010).

Os dados extraídos do sistema informatizado de desembaraço aduaneiro, combinados com o uso de tais contratos de desempenho, puderam reduzir as más práticas relacionadas aos funcionários aduaneiros (Cantens et al., 2010). Este sistema de contratos de desempenho, celebrado entre o Diretor Geral e um número de funcionários que ocupavam a linha de frente da operação, consiste em um projeto piloto e voluntário. A essência da utilização dos contratos de desempenho consiste em um acordo no qual as práticas dos oficiais de aduana são registradas e comunicadas ao Diretor Geral. Depois de alguns meses da implementação, os resultados percebidos já puderam ser destacados: diminuição da corrupção, aumento de receitas e menor tempo de desembaraço.

Todos os procedimentos aduaneiros foram substituídos pela atuação do sistema automatizado em Camarões. Este processo aboliu as chamadas "notas de liberação/lançamento", o que obrigava os despachantes ou importadores a retornarem aos servidores aduaneiros uma vez que já tinham pago as taxas devidas. Maior autonomia e também automação tiveram como consequência diversos avanços nos processos realizados nas aduanas (Cantens et al., 2010). Este caso de indicador de desempenho para contratos individuais surtiu efeito em Camarões, uma vez que foi traçada, previamente, a estratégia de combate à corrupção.

Analisando também outros fatores que podem colaborar para a melhoria no desempenho das operações, faz-se importante considerar a abordagem de gestão de risco. Por meio da identificação, análise, avaliação e tratamento dos riscos, a aduana administra as atividades do dia a dia que podem melhorar consideravelmente o seu desempenho. De fato, aplicando o gerenciamento de risco, as aduanas procuram aperfeiçoar a tomada de decisões e minimizar possíveis impactos, além de contribuir para a melhora da qualidade nos controles. Tal gerenciamento ajuda as administrações aduaneiras a manter o foco em suas prioridades e decisões. A administração aduaneira da Macedônia implementou o processo de gerenciamento de risco, conforme 
orientação da Organização Mundial das Aduanas (OMA ou WCO, World Customs Organization), o qual pode ser visto como um fator que colabora positivamente para a melhoria no desempenho no âmbito aduaneiro (Biljan \& Trajkov, 2012).

Neste contexto, o Quadro 3 apresenta uma síntese de referenciais em termos de indicadores-chave de desempenho no ambiente comercial, logístico e aduaneiro, utilizados em diferentes países.

A OMA (ou WCO) utiliza alguns dados e indicadores para medição, embora não sejam de aceitação universal, porque há argumentos contrários no sentido de que não se pode universalizar o uso de indicadores, pois há diferenças na realidade cultural e organizacional de cada país.

O Time Release Study (TRS), por exemplo, mede o tempo necessário para liberar uma carga e pode ser utilizado para medir o tempo de liberação da carga na aduana ou o tempo de liberação da carga de todas as agências da fronteira (ou órgãos que intervêm no controle físico de mercadorias). Este indicador pode identificar falhas e oportunidades de melhoria nos procedimentos fronteiriços e de logística (Ireland et al., 2011; WCO, 2012).

O Doing Business, criado pelo Banco Mundial, é outra metodologia de medição do tempo e custo associados à exportação e importação, bem como o número de documentos necessários para completar a transação. As economias mais desenvolvidas, por sua vez, destacam-se pela maior facilidade em realizar tais transações comerciais. Embora todo índice seja revestido de aspectos quantitativos, há um grau de subjetividade no tratamento das informações. De qualquer maneira, é um referencial de análise.

A facilidade para realizar negócios comerciais é um indicador relevante, pois, de acordo com o Banco Mundial, requisitos de documentação, procedimentos aduaneiros lentos, operações portuárias ineficientes e infraestrutura inadequada de transportes levam a custos que não agregam valor e, portanto, geram desperdícios e atrasos para as empresas. $\mathrm{O}$ fraco desempenho em qualquer um desses processos pode ter repercussões em toda a competitividade da cadeia de suprimentos. Nos relatórios do Doing Business produzidos de 2004 a 2014, não há registro de reformas realizadas pela aduana do Brasil. De 189 países estudados pelo relatório, no indicador "comércio entre as fronteiras" (que considera número de documentos, tempo e custo para importação e exportação,) o Brasil se situa na posição de número 124 (Banco Mundial, 2014).

Outro indicador que considera o serviço prestado pela aduana é o Logistics Performance Index (LPI), também organizado pelo Banco Mundial (The World Bank, 2014). Este ranking analisa comparativamente os avanços realizados no período por cada país, em termos de infraestrutura, competência logística, aduana e outros. No item aduana, é considerada a eficiência do processo de desembaraço, com indicadores como velocidade na liberação de mercadorias e previsibilidade. De 160 países analisados, o Brasil se situa na posição de número 65. No indicador específico relacionado à aduana, o Brasil se situa na $94^{\mathrm{a}}$ posição, a que menos passou por melhorias desde o início do estudo, em 2007 (The World Bank, 2014).

O Fórum Econômico Mundial também desenvolveu seu próprio índice de desempenho de questões relativas ao comércio internacional, chamado de Enabling Trade Index (ETI). Este índice considera alguns pilares, como: acesso ao mercado doméstico e internacional; eficiência da administração aduaneira, eficiência dos procedimentos de importação e exportação; transparência das ações tomadas pela administração aduaneira, entre outros (Lawrence et al., 2012). No estudo de 2014, do total de 138 países englobados, o Brasil se situa na posição de número $80 \mathrm{em}$ termos de administração aduaneira (WEF, 2014), com destaque para os procedimentos aduaneiros complicados na importação.

Outro estudo citado (CATT, 2014), elaborado em parceria pela Organização Mundial das Aduanas, Organização Mundial do Comércio, Banco Mundial e Câmara Internacional de Comércio, compreende um conjunto de 120 indicadores, divididos em diversas áreas e essas, por sua vez, categorizadas em dimensões, conforme dispostos do Quadro 4.

Do total de 120 indicadores do CATT, 43 são indicadores específicos relacionados a ações de enforcement/arrecadação e compliance/service charter. Destes 43, 19\% (8 deles) são indicadores relacionados a práticas de enforcement, enquanto $81 \%$ (35 indicadores) são relacionados a compliance. O restante dos indicadores é relacionado a controles,

Quadro 3. Estudos internacionais sobre indicadores-chave de desempenho aduaneiro.

\begin{tabular}{|c|c|c|c|c|c|}
\hline Organizações $\rightarrow$ & WCO & WB & WEF & WTO & ICC \\
\hline Time Release Study (TRS) & & & & & \\
\hline Doing Business - Trading Across Borders & & & & & \\
\hline Logistics Performance Index (LPI) & & & & & \\
\hline Enabling Trade Index (ETI) & & & & & \\
\hline Customs Assessment Trade Toolkit (CATT) & & & & & \\
\hline
\end{tabular}

WCO = Organização Mundial das Aduanas; WB = Banco Mundial; WEF = Fórum Econômico Mundial; WTO = Organização Mundial do Comércio; ICC = Câmara Internacional de Comércio. Elaborado pelos autores. 
Quadro 4. Distribuição relativa dos indicadores CATT, por áreas e dimensões.

\begin{tabular}{|c|c|c|c|c|c|c|c|c|c|}
\hline Áreas $\downarrow$ & Dimensões $\rightarrow$ & ن & 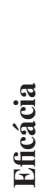 & 茎 & 馬 & 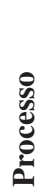 & 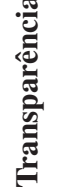 & 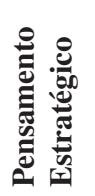 & Total \\
\hline
\end{tabular}

Não relacionados a enforcement/arrecadação e compliance/service charter 77

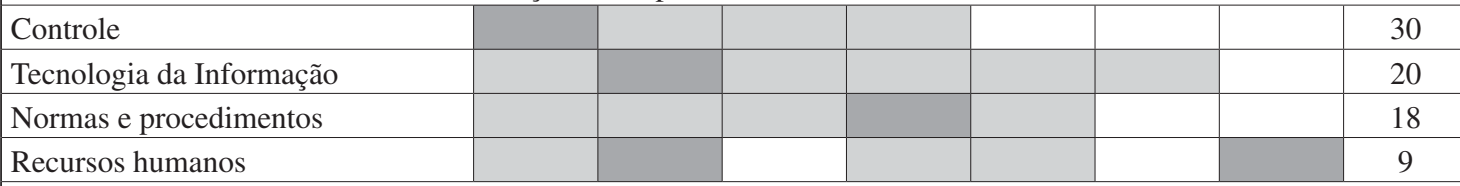

Relacionados a enforcement/arrecadação e compliance/service charter 43

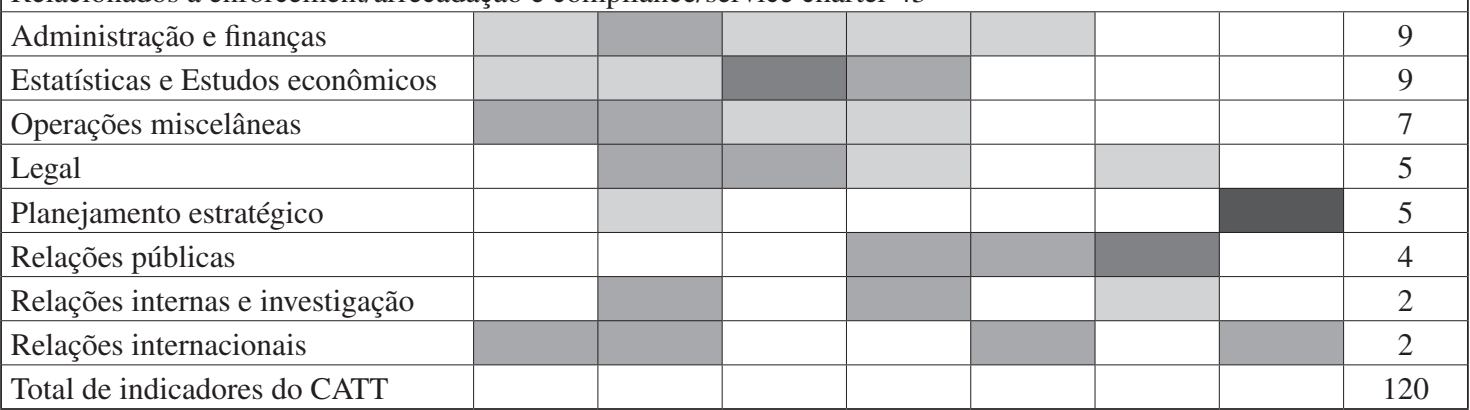

$0 \%$ a $25 \%=\square ; 25 \%$ a $50 \%=\square ; 50 \%$ a $75 \%=\square$

(CATT, 2014). Elaborado pelos autores.

normas, tecnologia da informação e política de recursos humanos, que podem ser aplicáveis em diferentes contextos e abordagens. No Quadro 4, também é possível ver relativamente em quais dimensões os indicadores por área estão mais relacionados, ou seja, qual a ênfase (dimensão) do indicador. É importante destacar que este estudo da CATT não tem a intenção de produzir um ranking de países, mas de coleta de melhores práticas utilizadas em todo o mundo, a ser utilizado como material para autoavaliação de cada administração aduaneira.

De forma complementar, o Quadro 5 apresenta alguns exemplos de indicadores relacionados a compliance (alguns dos 35 contidos na lista dos 120), coletados e estimulados por organizações (CATT, 2014). As boas práticas aduaneiras estão caminhando para a colaboração com o setor privado, ouvindo os operadores econômicos, redesenhando sua missão institucional e finalidade, sem descuidar do combate a práticas ilegais que geram ações de enforcement.

Ainda que os indicadores de desempenho devam considerar as realidades de cada país no seu processo de elaboração (Cantens et al., 2013), a observação de experiências semelhantes pode gerar aprendizados capazes de contribuir para um aprimoramento do próprio processo de elaboração de indicadores e de avaliações da aduana no Brasil e de avaliações em geral.

\section{A utilização de indicadores de desempenho na Aduana Brasileira}

O objetivo do uso de métricas no ambiente aduaneiro é melhorar sua eficácia, com a otimização da eficiência (Cantens et al., 2013). No entanto, são necessários o envolvimento e a motivação política rumo à aceitação da medição. No que tange à realidade da aduana brasileira, segundo dados do Plano de Modernização da Administração Aduaneira Brasileira (PMAB), "[...] o sistema de indicadores utilizados é muito criticado pelas unidades por não serem condizentes com suas realidades [...]" (Brasil, 2007, p. 14). Além disso, o relatório adverte que:

- Devido à diversidade da operação nas diversas aduanas no Brasil, a complexidade e as particularidades de cada localidade, os indicadores nem sempre traduzem as atividades e demandas das unidades.

- Há falta de transparência na interpretação e medição de desempenho, além do risco de manipulação dos dados.

- A percepção dos servidores públicos de que as unidades são avaliadas por indicadores voltados à arrecadação.

O PMAB prevê metas que poderiam se materializar em instrumentos de mensuração, mas que não ocorrem por possíveis contingências políticas. Dentre os objetivos estratégicos para a administração aduaneira brasileira, 
há o atendimento de excelência aos usuários da aduana, o aprimoramento da qualidade e a produtividade das atividades aduaneiras, e o aperfeiçoamento da política de gestão de pessoas. No entanto, não há indicadores associados divulgados, com ênfase nos servidores que trabalham na aduana. Como a avaliação é utilizada para melhorar as ações e para prestar contas aos cidadãos, e estando a Receita do Brasil alocada no Ministério da Fazenda, a preocupação com a prestação de contas recai, historicamente, na questão fiscalista, arrecadatória e de repressão aduaneira, com pouca ênfase na validação de dados relacionados à parte interessada, no caso de indicadores que beneficiam a fluidez de mercadorias e de interesse dos operadores econômicos. O Quadro 6 apresenta os indicadores utilizados pela RFB, no tocante à área aduaneira (e-SIC, 2014).

Nesse sentido, com base em informações do PMAB (Brasil, 2007), Visão de Futuro da Aduana Brasileira (Brasil, 2012c), Plano Plurianual 2012-2015 (Brasil, 2012b), relatórios de gestão 2012 das diversas regiões fiscais do Brasil (Brasil, 2012a) e consulta pública ao Sistema Eletrônico do Serviço de Informação ao Cidadão (e-SIC), relacionado à Lei de Acesso à Informação (e-SIC, 2014): a) Não há indicadores do tipo balanced scorecard (Niven, 2003), em que se observa a percepção do cliente/usuário, como os mencionados pela CATT (2014), a saber: número de reclamações aduaneiras relatadas por operadores econômicos; implementação de pesquisas de satisfação para operadores econômicos avaliarem o serviço da aduana; tempo médio para completar a inspeção física na importação. Lembrando Kaplan \& Norton (1992), o que não é medido, não é gerenciado. Kaplan \& Norton (1992) produziram o modelo de Balanced Score Card, enfatizando a necessidade de uma abordagem equilibrada (balanced), em termos de enfoques e medição de desempenho. A consideração somente da variável financeira, a despeito de outras variáveis, poderia comprometer a própria rentabilidade futura de uma organização.

b) Não se aplica o conceito de service charter.

c) Os controles mais observáveis e publicados em relatórios e estudos gerenciais da RFB tratam de indicadores relacionados a temas de enforcement. Entre eles: índice de gestão de

Quadro 5. Exemplos de Indicadores de Desempenho relacionados a compliance, utilizados em aduanas de melhores práticas mundiais.

\begin{tabular}{|c|}
\hline a. Percepção da corrupção ${ }^{1}$ \\
\hline b. Satisfação dos clientes ${ }^{1}$ \\
\hline c. Declarações de importação submetidas sem papel ${ }^{2}$ \\
\hline d. Operadores econômicos com perfis de risco predefinidos ${ }^{2}$ \\
\hline e. Tempo médio para completar a conferência física na importação \\
\hline f. Desembaraço aduaneiro que teve o desempenho dentro dos limites estabelecidos ${ }^{2}$ \\
\hline g. Declarações referentes aos bens importados que foram desembaraçadas antes da chegada da carga ${ }^{2}$ \\
\hline h. Número de reclamações aduaneiras relatadas por operadores econômicos \\
\hline i. Declarações desembaraçadas automaticamente para operadores econômicos certificados ${ }^{2}$ \\
\hline j. Tempo de desembaraço de declarações relativas à remessa expressa (courier) \\
\hline k. Manifestos de cargas que foram submetidos eletronicamente à aduana antes da chegada da carga ${ }^{2}$ \\
\hline
\end{tabular}

${ }^{1}$ Survey com operadores econômicos; ${ }^{2}$ Medido em termos percentuais. Customs Assessment Trade Toolkit (CATT, 2014). Elaborado pelos autores.

Quadro 6. Indicadores utilizados pela Aduana do Brasil.

\begin{tabular}{|l|}
\hline a. Grau de cumprimento de obrigações aduaneiras na importação \\
\hline b. Índice global da fiscalização aduaneira (IGFA) \\
\hline c. Grau de eficácia da seleção para fiscalização no despacho de importação \\
\hline d. Grau de fluidez do despacho de importação \\
\hline e. Tempo médio bruto no despacho aduaneiro de exportação \\
\hline f. Valor das apreensões provenientes de operações de vigilância e repressão aduaneira \\
\hline g. Índice de realização da meta das operações de vigilância e repressão aduaneira ${ }^{2}$ \\
\hline h. Grau de eficácia da seleção para fiscalização aduaneira de intervenientes no comércio exterior $(\text { IGES })^{2}$ \\
\hline
\end{tabular}

${ }^{1}$ Medido em dias; ${ }^{2}$ Medido em termos percentuais; ${ }^{3}$ Medido em milhões de reais. Serviço de Informação ao Cidadão (e-SIC, 2014).

Elaborado pelos autores. 
mercadorias apreendidas (IGMA), indicador global de fiscalização (IGF), cumprimento de obrigações aduaneiras na importação, índice de realização da meta das operações de vigilância e repressão aduaneira, valor das apreensões provenientes de operações de vigilância e repressão aduaneira, dentre outros.

d) Há poucas métricas referentes a ações de compliance, como o grau de fluidez do despacho de importação.

e) Há um novo indicador, desde 2012, que é o percentual de serviços atendidos com tempo médio de espera menor ou igual a 15 minutos, mas este indicador não é utilizado na área aduaneira, somente para a área de tributos internos da Receita Federal.

f) Não há indicadores transversais, considerando a atuação de outros órgãos da administração pública nos controles de entrada e saída de mercadorias do país. A legislação brasileira estabelece a precedência da fiscalização aduaneira para a Receita Federal do Brasil, mas no ambiente aduaneiro também atuam outros órgãos com responsabilidades distintas, como é o caso do Ministério da Agricultura, Pecuária e Abastecimento (MAPA), dentre outros, que atua na fiscalização das embalagens de madeiras e pallets que chegam ao Brasil com a mercadoria estrangeira.

O próprio Sindicato Nacional dos Auditores Fiscais da Receita Federal (UNAFISCO, 2006, p. 4) enfatizou que:

[...] o enfoque administrativo equivocado acabou deslocando a aduana oficial do Brasil, a cargo da SRF (sic), para uma função meramente arrecadatória, dando a ela um grau de importância proporcional ao quantum de tributos arrecadados [...] Sabe-se, no entanto, que o tributo aduaneiro tem função extrafiscal e que a missão de um sistema aduaneiro eficiente transcende essa função arrecadatória.

Pode-se concluir que há pouco alinhamento entre objetivos e mensuração em sentido abrangente na aduana brasileira. Segundo a Unafisco (2006), a construção de uma aduana atuante é tarefa que interessa à sociedade brasileira. Embora haja um reconhecimento de que muitos esforços têm sido implementados no sentido de dar eficiência à aduana brasileira, eles acabam por não cumprir seus objetivos, basicamente por não estarem vinculados àquilo que a Unafisco chama de "finalidade institucional" (UNAFISCO, 2006).

Os Estados nacionais sempre exercerão a função normativa, reguladora e controladora de seus fluxos comerciais. Nas palavras de Sosa (1994, p. 111), o que "[...] varia é a amplitude dessa regulação: ostensiva ou abrandada, mas sempre presente [...]". Sosa (2014) também acrescenta que o debate sobre a aduana independente da Receita Federal é um tema que entra e sai da pauta de discussões aduaneiras, porque a aduana brasileira não percebeu que o disciplinamento dos fluxos de comércio exterior por meio de atividades de regulação, controle e fiscalização caminham além dos interesses tributários. Historicamente tem sido desta forma. A reforma da gestão da aduana brasileira passa pelo equilíbrio na adoção de indicadores de desempenho com ênfases distintas.

A Figura 2 ("a" e "b") ilustra a diferença na abordagem de utilização de indicadores de desempenho, entre as melhores práticas coletadas em CATT (2014) e as praticadas pela aduana brasileira, considerando o número e a qualidade de indicadores, dentre os de compliance e enforcement, na coletânea de 43 (dos 120) indicadores de CATT (2014) e os 8 (oito) indicadores utilizados pela aduana do Brasil (Quadro 6).

Pelos relatórios produzidos pela RFB (Brasil, 2007, 2012a), é possível perceber preocupações com o

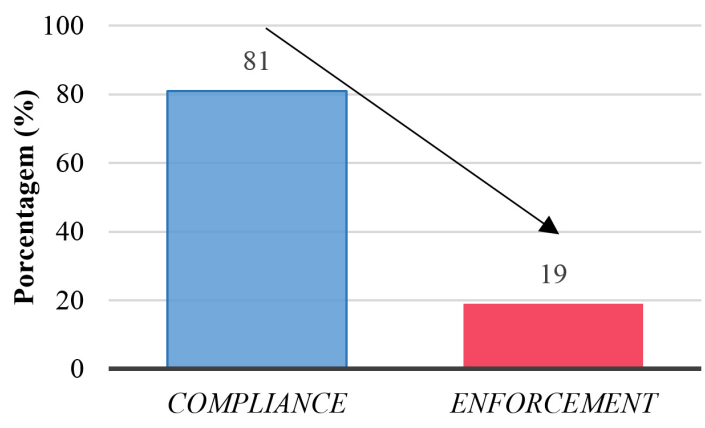

(a) Indicadores CATT

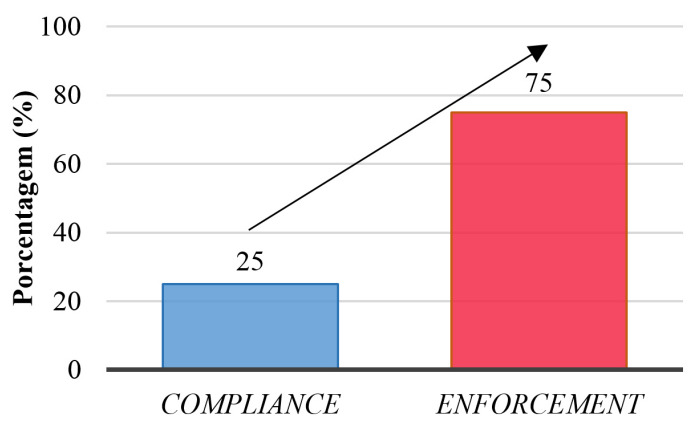

(b) Indicadores Aduana do Brasil

Figura 2. Comparativo de utilização de indicadores, CATT x Aduana do Brasil. Elaborado pelos autores com base em Customs Assessment Trade Toolkit (CATT, 2014) e no Serviço de Informação ao Cidadão (e-SIC, 2014). A porcentagem se refere ao total de indicadores utilizados em cada contexto. 
fluxo internacional de mercadorias, a globalização e a participação em cadeias de suprimentos internacionais existem, mas não são concretizadas em termos de metas a serem atingidas. É importante considerar indicadores que tenham o objetivo de medir a qualidade do serviço e, dessa maneira, melhorar o nível de prestação e atenção ao cliente. Neste sentido, em relação aos resultados, os indicadores utilizados não mostram eficiência, eficácia e efetividade com relação a iniciativas de compliance e service charter.

É interessante lembrar que várias reformas nas administrações aduaneiras do mundo passaram a utilizar o conceito de "service charter", tal como utilizado no Reino Unido desde os anos 1980. McGuire (2001) descreve "service charter" como uma nova estratégica de gestão pública que visa mudar o foco da cultura do serviço prestado, para o serviço focado nas necessidades do contribuinte. No Brasil, a prestação do serviço aduaneiro é orientada antes à punição que ao esclarecimento ao contribuinte, sendo que o público-alvo não tem o enfoque prioritário de cliente (Félix et al., 2011). Uma reforma que promova maior previsibilidade e simplificação, provavelmente contribuiria para uma redução dos custos logísticos e aduaneiros associados ao comércio internacional e, assim, aumentaria os fluxos comerciais entre países (Souza \& Burnquist, 2011; Hummels, 2001).

\section{Considerações finais}

O objetivo deste artigo foi discutir o uso de indicadores de desempenho na aduana do Brasil e seus impactos na gestão de cadeias de suprimentos internacionais.

A medição de desempenho é importante para que riscos e oportunidades sejam identificados. Dessa forma, o serviço a ser oferecido ao cliente pode ser melhorado e quantificado. No caso da medição de desempenho nas aduanas, novas demandas precisam ser contempladas na elaboração de estratégias de políticas públicas, com indicadores relacionados a práticas de compliance e service charter, observadas as demandas dos diferentes stakeholders. A existência de indicadores nesta área, sem a devida ênfase estratégica, não completa o ciclo de política pública, pois não provoca resultados em termos de eficiência e efetividade, bem como não contribui para cadeias de suprimentos internacionais que passam pelo Brasil. $\mathrm{O}$ indicador de desempenho deve ser um instrumento para validar ou provocar revisões na estratégia, bem como monitorá-la e avaliá-la, provocando reformas na gestão aduaneira.

Alguns indicadores praticados pela aduana brasileira não estão efetivamente difundidos e relacionados com a estratégia da organização, como nível de serviço ao cliente e tempo de resposta às consultas dos contribuintes. Outros estão relacionados a esta esfera de análise, como tempo total de liberação aduaneira das mercadorias que chegam ao país, mas com uma estratégia com ênfase fiscalista e arrecadatória, na imposição de normas e controles (enforcement).

Historicamente, o Ministério da Fazenda entende o operador econômico como um contribuinte. O novo estágio de competição internacional, em que se considera a integração de setores industriais em cadeias globais de valor, passa pelo aumento de competitividade em cada elo da cadeia de suprimentos, inclusive na aduana. $\mathrm{O}$ elo mais lento acaba condicionando a velocidade de toda a cadeia, gerando um gargalo (Mizgier et al., 2013). Este artigo não aborda a discussão de desmembramento da aduana brasileira da Receita Federal (Ministério da Fazenda), mas sim a utilização de uma abordagem equilibrada em termos de medidas relacionadas à arrecadação/controle, com indicadores que interessam ao operador econômico (cliente), e que permitem a fluidez da carga com mais eficácia pelas fronteiras.

No Brasil, a falta de métricas preestabelecidas em vários indicadores (e.g. credibilidade, produtividade, burocracia, disponibilidade de fiscais, tempo de resposta do fiscal, entre outros) provoca instabilidade no ambiente aduaneiro, retirando competitividade de cadeias de suprimentos internacionais que passam pelo Brasil e dificultando a necessária integração entre os diferentes elos da cadeia. Sendo assim, o que tem sido medido na aduana nacional não está em consonância com as melhores práticas mundiais, o que enseja a busca por reformas no ambiente aduaneiro.

A reforma da gestão aduaneira passa obrigatoriamente pela busca do equilíbrio na utilização de indicadores e não pela discussão de alocação de competência no seio da estrutura de governança dos ministérios no Brasil. A gestão de mudança da Receita Federal passa pela utilização com ênfase equilibrada em indicadores de desempenho de enforcement e compliance/service charter.

A alteração da estratégia da aduana brasileira para uma ênfase no equilíbrio em seus indicadores pode contribuir para um esforço no sentido da economicidade e na utilização de recursos públicos com o menor custo possível. Definir benefícios e indicadores para compliance reduz a necessidade de recursos para enforcement. Esta estratégia potencializa a alocação de recursos humanos onde eles são mais necessários, o que mostraria maior qualidade do uso de recursos públicos. Para isso, os indicadores para compliance devem ser definidos, mensurados, valorizados, implementados, monitorados e validados no Brasil. A utilização de indicadores de desempenho em áreas de compliance está em sintonia com os interesses dos stakeholders, que consideram, além do interesse do próprio Estado, os interesses dos prestadores de serviço, importadores, exportadores, operadores logísticos e demais empresas de cadeias de suprimentos. Esta mudança de abordagem e de 
consideração dos indicadores de desempenho está em sintonia com as boas práticas na área de reforma e modernização aduaneira em todo o mundo.

Outro fator a se considerar no Brasil é a falta de recompensas para os servidores que cumprem as metas. Metas não claras não são capazes de gerar satisfação no seu cumprimento e não proporcionam incentivos à ação. Além do mais, para a administração aduaneira atual, o indicador mais relevante é a arrecadação. Todos os outros indicadores não afetam diretamente a administração aduaneira, sendo que a gestão da cadeia de suprimentos e o interesse do operador econômico não são levados em consideração diretamente, assim como está inserido no pacote de competitividade da Organização Mundial das Aduanas (OMA).

Como as empresas têm níveis de serviço acordados com seus clientes (muitas vezes determinados em contratos), é importante que toda a cadeia de suprimentos esteja alinhada e que todas as atividades estejam planejadas de acordo com o tempo total necessário para concluir a produção dos itens finais. Melhorando a qualidade do serviço oferecido ao cliente, as organizações têm maiores possibilidades de competir no mercado nacional e global, trazendo benefícios importantes para o País.

Para o desenvolvimento de trabalhos futuros, este artigo recomenda a prática de simulação que utiliza métodos quantitativos, com a introdução de variáveis aplicadas à questão do serviço focado no cliente, bem como a avaliação de seus impactos e resultados em diferentes pontos de controle do território nacional. Iniciativas recentes em termos de implementação do programa de Operador Econômico Autorizado (OEA), revisão da legislação de Linha Azul e Recof, implantação gradativa do Portal Único de Comércio Exterior e parceria com o Instituto Pró-Modernização do Comércio Exterior do Brasil (Aliança Procomex), dentre outras, pode indicar um novo caminho para uma ênfase maior nos indicadores de "compliance" na Aduana do Brasil.

\section{Agradecimentos}

Os autores agradecem à FAPESP, processo número 2012/06837-7, o apoio financeiro e institucional, ao CNPq, processo número 405608/2012-8, bem como aos avaliadores os comentários e sugestões.

\section{Referências}

Abernethy, M. A., Horne, M., Lillis, A. M., Malina, M. A., \& Selto, F. H. (2005). A multi-method approach to building causal performance maps from expert knowledge. Management Accounting Research, 16(2), 135-155. http:// dx.doi.org/10.1016/j.mar.2005.03.003.

Appeals, T., \& Struye de Swielande, H. (1998). Rolling back the frontiers: the customs clearance revolution. The
International Journal of Logistics Management, 9(1), 111-118. http://dx.doi.org/10.1108/09574099810805780.

Arvis, J. F., Mustra, M. A., Ojala, L., Shepherd, B., \& Saslavsky, D. (2012). Connecting to compete: trade logistics in the global economy. The logistics performance index and its indicators. Washington: International Trade Unit.

Balasubramanian, S., \& Gupta, M. (2005). Structural metrics for goal based business process design and evaluation. Business Process Management Journal, 11(6), 680-694. http://dx.doi.org/10.1108/14637150510630855.

Ballou, R. H. (2006). Gerenciamento da cadeia de suprimentos: logística empresarial (2 ed.). Porto Alegre: The Bookman.

Banco Mundial (2014). Doing business, trading across borders. Recuperado em 12 de março de 2014, de http://www.doingbusiness.org/data/exploretopics/ trading-across-borders.

Basaldua, R. X. (2007). La Aduana: concepto y funciones esenciales y contingentes. Revista de Estudios Aduaneros, 18(1), 37-54.

Baumann, R. (Org.). (1996). O Brasil e a economia global. Rio de Janeiro: Campus SOEET.

Beamon, B. M. (1999). Measuring supply chain performance. International Journal of Operations \& Production Management, 19(3), 275-292. http://dx.doi. org/10.1108/01443579910249714.

Biljan, J., \& Trajkov, A. (2012). Risk management and Customs performance improvements: The case of the Republic of Macedonia. Procedia: Social and Behavioral Sciences, 44, 301-313. http://dx.doi.org/10.1016/j. sbspro.2012.05.033.

Bourne, M., Mills, J., Wilcox, M., Neely, A., \& Platts, K. (2000). Designing, implementing and updating performance measurement systems. International Journal of Operations \& Production Management, 20(7), 754-771. http://dx.doi. org/10.1108/01443570010330739.

Bowersox, D. J., Closs, D. J., \& Cooper, M. B. (2006). Gestão logística de cadeias de suprimentos. Porto Alegre: Bookman,

Brasil, Ministério da Fazenda, Receita Federal do Brasil (2007). Plano de Modernização da Administração Aduaneira do Brasil-PMAB. Brasília: Receita Federal do Brasil, Price Water House e Coopers.

Brasil, Tribunal de Contas da União (2009). Indicadores de desempenho. Brasília: TCU.

Brasil, Ministério da Fazenda, Secretaria da Receita Federal do Brasil (2012a). Relatório de gestão do exercício 2012. Brasília: Ministério da Fazenda.

Brasil, Ministério do Planejamento, Orçamento e Gestão (2012b). Plano Plurianual 2012-2015. Brasília: Ministério do Planejamento, Orçamento e Gestão.

Brasil, Ministério da Fazenda, Secretaria da Receita Federal do Brasil (2012c). Visão de futuro para a aduana brasileira. Brasília: Ministério da Fazenda.

Brignall, S., \& Modell, S. (2000). An institutional perspective on performance measurement and management in the 'new public sector'. Management Accounting Research, 11(3), 281-306. http://dx.doi.org/10.1006/mare.2000.0136. 
Cantens, T., Ireland, R., \& Raballand, G. (2013). Reform by numbers: measurement applied to customs and tax administrations in developing countries. Washington: The World Bank.

Cantens, T., Raballand, G., \& Bilangna, S. (2010). Reforming customs by measuring performance: reflections based on the Cameroon example. In PICARD Conference. Abu Dhabi.

Child, J. (1972). Organizational structure, environment and performance: The role of strategic choice. Sociology, 6(1), 1-22. http://dx.doi.org/10.1177/003803857200600101.

Child, J. (1997). Strategic choice in the analysis of action, structure, organizations and environment: retrospect and prospect. Organization Studies, 18(1), 43-76. http:// dx.doi.org/10.1177/017084069701800104.

Chin, K. S., Lo, K. C., \& Leung, J. P. F. (2010). Development of user satisfaction-based knowledge management performance measurement system with evidential reasoning approach. Expert Systems with Applications, 37(1), 366-382. http:// dx.doi.org/10.1016/j.eswa.2009.05.051.

Cho, D. S., Moon, H. C., \& Kim, M. Y. (2007). Characterizing international competitiveness in international business research: A MASI approach to national competitiveness. Seoul: Elsevier.

Cook, D. J., Mulrow, C. D., \& Haynes, R. B. (1997). Systematic reviews: synthesis of best evidence for clinical decisions. Annals of Internal Medicine, 126(5), 376-380. http:// dx.doi.org/10.7326/0003-4819-126-5-199703010-00006. PMid:9054282

Cooper, M. C., Lambert, D. M., \& Pagh, J. D. (1997). Supply chain management: more than a new name for logistics. The International Journal of Logistics Management, 8(1), 1-14. http://dx.doi.org/10.1108/09574099710805556.

Corrêa, H. L. (2010). Gestão de redes de suprimento: integrando cadeias de suprimento no mundo globalizado. São Paulo: Atlas.

Customs Assessment Trade Toolkit - CATT (2014). Good practices approach. Recuperado em 12 de março de 2014, de http://customscatt.org/.

De Toni, A., \& Tonchia, S. (2001). Performance measurement systems: models, characteristics and measures. International Journal of Operations \& Production Management, 21(1-2), 46-71. http://dx.doi.org/10.1108/01443570110358459.

Djankov, S., Freund, C., \& Pham, C. S. (2010). Trading on time. The Review of Economics and Statistics, 92(1), 166-173. http://dx.doi.org/10.1162/rest.2009.11498.

Dye, T. R. (1976). Policy analysis: what governments do, why they do it, and what difference it makes. Tuscaloosa: University of Alabama Press.

Félix, R., Félix, P. P., \& Timóteo, R. (2011). Balanced Scorecard: adequação para a gestão estratégica nas organizações públicas. Revista do Serviço Público, 62(1), 51-74.

Forrester, J. W. (1961). Industrial dynamics. London: MIT Press.

Frey, K. (2000). Políticas públicas: um debate conceitual e reflexões referentes à prática da análise de políticas públicas no Brasil. Planejamento e Políticas Públicas, 21, 212-159.

Global Customs Initiative-GCI (2008). Structuring customs modernization. Bélgica: World Customs Organization.

Gregorio, R. M. (2001). Um modelo organizacional para a interiorização da aduana brasileira: perspectiva perante o Mercosul e a administração pública gerencial (Dissertação de mestrado). Escola Brasileira de Administração Pública e de Empresas, Fundação Getúlio Vargas. Rio de Janeiro.

Griffis, S., Goldsby, T., Cooper, A., \& Closs, D. (2007). Aligning logistics performance measures to the information needs of the firm. Journal of Business Logistics, 28(2), 35-56. http://dx.doi.org/10.1002/j.2158-1592.2007.tb00057.x.

Gubin, A. (2011). Developing performance measurement for the Russian Customs Service. World Customs Journal, 5(2), 45-61.

Gültekin, S. (2011). New public management: is it really new? International Journal of Human Sciences, 8(2), 344-358.

Gunasekaran, A., Patel, C., \& Mcgaughey, R. E. (2004). A framework for supply chain performance measurement. International Journal of Production Economics, 87(3), 333-347. http://dx.doi.org/10.1016/j.ijpe.2003.08.003.

Gunasekaran, A., Patel, C., \& Tirtiroglu, E. (2001). Performance measures and metrics in a supply chain environment. International Journal of Operations \& Production Management, 21(1/2), 71-87. http://dx.doi. org/10.1108/01443570110358468.

Haughton, M. A., \& Desmeules, R. (2001). Recent reform in customs administration. International Journal of Logistics Management, 12(1), 65-82. http://dx.doi. org/10.1108/09574090110806235.

Heaver, T. D. (1992). The role of customs administration in the structure and efficiency of international logistics. International Journal of Logistics Management, 3(1), 63-72. http://dx.doi.org/10.1108/09574099210804813.

Hummels, D. (2001). Time as a Trade Barrier (GTAP Working Paper, No. 18, pp. 1-35). West Lafayette: Center for Global Trade Analysis, Purdue University.

Ireland, R., \& Matsudaira, T. (2011). Reform instruments, tools, and best practices approaches. In G. McLinden, E. Fanta, D. Widdowson, \& T. Doyle (Eds.), Border management modernization. Washington: The World Bank.

Ireland, R., Cantens, T., \& Yasui, T. (2011). An overview of performance measurement in customs administrations (WCO Research Paper, No. 13, pp. 1-10). Brussels: World Customs Organization.

Jannuzzi, P. M. (2003). Indicadores sociais no Brasil: conceitos, fontes de dados e aplicações. Campinas: Editora Alínea.

Jannuzzi, P. M. (2005). Indicadores para diagnóstico, monitoramento e avaliação de programas sociais no Brasil. Revista do Serviço Público, 56(2), 137-160.

Jones, C. O. (1970). An introduction to the study of public policy. Belmont: Wadsworth Publishing.

Kaminsky, P., Simchi-Levi, D., \& Simchi-Levi, E. (2003). Cadeia de suprimentos - projeto e gestão. Porto Alegre: Bookman. 
Kaplan, R. S., \& Norton, D. P. (1992). The balanced scorecard-measures that drive performance. Harvard Business Review, 70(1), 71-79. PMid:10119714.

Kennerley, M., \& Neely, A. (2002). A framework of the factors affecting the evolution of performance measurement systems. International Journal of Operations \& Production Management, 22(11), 1222-1245. http:// dx.doi.org/10.1108/01443570210450293.

Lacerda, R. T. O., Ensslin, L., \& Ensslin, S. R. (2012). Uma análise bibliométrica da literatura sobre estratégia e avaliação de desempenho. Gestão \& Produção, 19(1), 59-78. http://dx.doi.org/10.1590/S0104-530X2012000100005.

Lai, K., Ngai, E., \& Cheng, T. (2002). Measures for evaluating supply chain performance in transport logistics. Transportation Research Part E, Logistics and Transportation Review, 38(6), 439-456. http://dx.doi. org/10.1016/S1366-5545(02)00019-4.

Lawrence, R. Z., Hanouz, M. D., \& Doherty, S. (2012). The Global Enabling Trade Report 2012: reducing supply chain barriers. Genebra: World Economic Forum.

Levitt, T. (1983). The globalization of markets. Harvard Business Review. Recuperado em 27 abril de 2005, de https://hbr.org/1983/05/the-globalization-of-markets/ar/1.

Lima, P. S. (2008). As Aduanas como áreas indispensáveis à Segurança Nacional: identificação, propostas e critérios de utilização. Revista da Escola Superior de Guerra, 24(49), 160-178.

Liu, L., \& Yue, C. (2013). Investigating the impacts of time delays on trade. Food Policy, 39(1), 108-114. http://dx.doi. org/10.1016/j.foodpol.2013.01.001.

Matsuda, S. (2012). The Time Release Study as a performance measurement tool for a supply chain and an international corridor. World Customs Journal, 6(1), 79-92.

McGuire, L. (2001). Service Charters - Global Convergence or National Divergence? A comparison of initiatives in Australia, the United Kingdom and the United States. Public Management Review, 3(4), 493-524. http://dx.doi. org/10.1080/14616670110071856.

Meny, Y., \& Thoenig, J. C. (1992). Las políticas públicas. Barcelona: Editora Ariel.

Mestriner, C. A. (2010). Identificação e análise dos fatores críticos que interferem na relação entre o suprimento global e a produção enxuta (Dissertação de mestrado). Escola de Engenharia de São Carlos, Universidade de São Paulo, São Carlos.

Mizgier, K. J., Jüttner, M. P., \& Wagner, S. M. (2013). Bottleneck identification in supply chain networks. International Journal of Production Research, 51(5), 1477-1490. http://dx.doi.org/10.1080/00207543.2012 .695878 .

Modell, S. (2001). Process performance measurement and institutional processes: a study of managerial responses to public sector reform. Management Accounting Research, 12(4), 437-464. http://dx.doi.org/10.1006/mare.2001.0164.

Morini, C., \& Leoce, G. (2011). Logística internacional segura: operador econômico autorizado e a gestão de fronteira no século XXI. São Paulo: Atlas.
Morini, C., Barassa, E., Maurício, M. P. G., Moretti, A. C., \& Porto, P. C. S. (2014). Aduana do Brasil e competitividade: uma comparação em termos de eficiência relativa. GEPROS: Gestão da Produção, Operações e Sistemas, 9(3), 1-13.

Nguyen, D. X. (2012). Demand uncertainty: Exporting delays and exporting failures. Journal of International Economics, 86(2), 336-344. http://dx.doi.org/10.1016/j. jinteco.2011.10.007.

Niven, P. R. (2003). Balanced scorecard step-by-step for government and nonprofit agencies. New York: John Wiley \& Sons.

Parker, C. (2000). Performance measurement. Work Study, 49(2), 63-66. http://dx.doi.org/10.1108/00438020010311197.

Pascal, L. (2010). Performance measurement: identifying appropriate methods for measuring and evaluating the performance of customs. In PICARD Conference. Abu-Dhabi.

Piotrowicz, W., Cuthbertson, R., \& Islei, G. (2011). Performance measurement and benchmarking in the supply chain: literature review. Oxford: University of Oxford.

Pomfret, R. (2010). Trade facilitation and the measurement of trade costs. Journal of International Commerce, Economic and Policy, 1(1), 145-163.

Portugal-Perez, A., \& Wilson, J. S. (2010). Export performance and trade facilitation reform: hard and soft infrastructure (Policy Research Working Paper, No. 5261, pp. 1-55). Washington: The World Bank.

Roth Deubel, A. N. (2006). Políticas públicas: formulación, implementación y evaluación. Bogotá: Ediciones Aurora.

Ruigrok, W., \& van Tulder, R. (1995). The logic of international restructuring. London: Routledge.

Sawhney, R., \& Sumukadas, N. (2005). Coping with customs clearance uncertainties in global sourcing. International Journal of Physical Distribution \& Logistics Management, 35(4), 278-295. http://dx.doi. org/10.1108/09600030510599931.

Serafim, M. P., \& Dias, R. B. (2012). Análise de política: uma revisão da literatura. Cadernos Gestão Social, 3(1), 121-134.

Seth, P. (2010). Performance measurement in customs. Mauritius Islands: Mauritius Revenue Authority.

Shepherd, B., \& Wilson, J. S. (2009). Trade facilitation in ASEAN member countries: Measuring progress and assessing priorities. Journal of Asian Economics, 20(4), 367-383. http://dx.doi.org/10.1016/j.asieco.2009.03.001.

Silva, E. L., \& Menezes, E. M. (2005). Metodologia da pesquisa e elaboração de dissertação (4 ed.). Florianópolis: Universidade Federal de Santa Catarina.

Sindicato Nacional dos Auditores Fiscais da Receita do Brasil - UNAFISCO (2006). Considerações sobre a Aduana brasileira. Brasília: Departamento de Estudos Técnicos.

Sistema Eletrônico do Serviço de Informação ao Cidadão e-SIC (2014). Lei de acesso à Informação. Recuperado em março de 2014, de http://www.acessoainformacao.gov. $\mathrm{br} /$ sistema/site/index.html?ReturnUrl=\%2fsistema\%2f. 
Sosa, R. B. (1994). Considerações sobre a Aduana do Brasil. Revista do Serviço Público, 118(3), 1-11.

Sosa, R. B. (2014). A tutela aduaneira relativa os interesses de ordem pública. Recuperado em 22 de março de 2014, de http://jus.com.br/artigos/3026/a-tutela-aduaneirarelativa-aos-interesses-de-ordem-publica.

Souza, M. J. P., \& Burnquist, H. L. (2011). Facilitação de comércio e impactos sobre o comércio bilateral. Estudos Econômicos, 41(1), 91-118.

The World Bank (2014). Logistics Performance Index: International LPI global ranking. Recuperado em 22 de março de 2014, de http://lpi.worldbank.org/international/ global/2014.

van Stolk, C., \& Wegrich, K. (2008). Convergence without diffusion? A comparative analysis of the choice of performance indicators in tax administration and social security. International Review of Administrative Sciences, 74(4), 589-614. http://dx.doi. org/10.1177/0020852308098470.

VITAL, J. M. (2014). História da administração tributária e aduaneira no Brasil: de 1500 à Receita Federal. Revista da Receita Federal: Estudos Tributários e Aduaneiros, 1(1), 10-27.

World Customs Organization - WCO (2012). Organizational Performance Measurement (The Development Compendium). Brussels: WCO. 28 p.

World Economic Forum - WEF (2014). The Global Enabling Trade Report. Recuperado em 26 de abril de 2014, de http://www.weforum.org/reports/ global-enabling-trade-report-2014. 